\title{
Blockchain for Corporate Renewable Energy Procurement-Potential for Verification of Renewable Energy Certificates
}

\author{
Jerry I.-H. Hsiao \\ University of Macau, Macau SAR, China; \\ University of London, London, UK
}

\begin{abstract}
The market for renewable energy among corporations has been driven by corporate social responsibility (CSR) objectives, continued cost reductions in renewable technologies, and more flexible regulation. As such, corporations have signed agreements to purchase $5.4 \mathrm{GW}$ of clean energy globally in 2017, up from $4.3 \mathrm{GW}$ in 2016. To date, 127 companies have committed to the RE100 initiative, where signatories commit to power $100 \%$ of their electricity demand from renewable energy. Liberalized power markets has lead companies headquartered in the U.S. (e.g., Facebook, Google, and Apple) to become the world's leading players in renewable power procurement. Physical/virtual power purchase agreements (PPAs) are now the favored tool for bringing new renewable energy onto the grid but mechanisms, such as green tariffs, renewable energy certificates (RECs), and direct investments also play a role. This paper focuses on REC and explores issues regarding the verification of RECs on the market. In light of the potential fraud (e.g., double counting) of RECs, this paper provides a forward looking proposal to eliminate this issue via the use of blockchain technology.
\end{abstract}

Keywords: blockchain, smart contract, renewable energy, REC verification

\section{Introduction}

Corporate interest in powering their operations with renewable energy (RE) has grown substantially in recent years, with large purchasers having noticeable impact on RE development in some locations. Almost 50\% of U.S. renewable energy generation in the last 17 years has stemmed from Renewable Portfolio Standards (RPSs). ${ }^{1}$ As of March 2018, 127 companies have committed to the RE100 initiative, where signatories commit to power $100 \%$ of their electricity demand from renewable energy. A variety of global companies headquartered in Europe, Asia, and North America have set targets to achieve 100\% RE consumption while many others have established smaller, but substantial goals.

Jerry I.-H. Hsiao, Ph.D., assistant professor, Faculty of Law, University of Macau, Macau SAR, China; University of London, London, UK.

1 See the RE100 Initiative, http://there100.org/re100, and the We Mean Business Coalition, https://www.wemeanbusinesscoalition.org/take-action/commit-100-renewable-power (RPS requires electric utilities and other retail electric providers to supply a specified minimum percentage of customer demand with eligible sources of renewable electricity). 


\section{Why Are Corporations Buying Renewable Energy?}

Traditionally, corporations are being established for profit maximization and responsibility to its shareholders. However, this is no longer the rule as business nowadays, drawing attention to socially and environmentally responsible practices with increasing consumer demand and investment value. ${ }^{2}$ These companies are termed "public benefit corporations" (PBCs). PBCs are a new type of business structure that empowers the corporation's leadership to balance public benefits against shareholder profits. ${ }^{3}$ Directors in a PBC are required to balance the company's private interests with the public interests of other stakeholders. ${ }^{4}$ Since PBCs seek to implement practices which advance the public benefit, it is crucial that they are effectively verified. $^{5}$

The RE100 Initiative is just one driver of PBCs to become more environmentally friendly. With the passing of the 2015 Paris Agreement on Climate Change and the adoption of the United Nations' Sustainable Development Goals (SDG), businesses worldwide are under increasing pressure to reduce their carbon footprint. A RE procurement strategy can be a valuable tool for demonstrating a company's commitment towards sustainability, which could help enhance its reputation and branding.

There are also a number of other reasons why companies might want to use renewable energy. Firstly, renewable energy can be cost effective. Due to the rapid reduction in the cost of renewable energy technologies, they can be the cheapest form of energy available on the grid under the right market conditions. Secondly, pursuing renewable energy allows a corporate buyer to diversify its energy supply sources across multiple technologies and contractual structures. This diversification helps to protect against energy availability concerns. Thirdly, taking the proactive step to procure renewable energy can help a company gain valuable experience meeting potential regulatory requirements in the future. This in turn could help the company avoid potential penalties from environmental regulations.

\section{Renewable Energy Procurement Mechanisms}

Corporations have used a variety of means to buy renewable energy, such as on-site generation, renewable energy certificate (REC), power purchase agreement, and green tariffs. The local regulatory context hugely influences the range of available options for corporations to cost-effectively purchase renewable energy from off-site generators. The focus of this paper will solely be on RECs.

\section{Renewable Energy Certificates}

When electricity is generated, the electrons added to the grid are indistinguishable between those produced by a renewable and a non-renewable source. Hence, one way for consumers to claim renewable electricity consumption is through the use of Renewable Energy Certificates (RECs). ${ }^{6}$ RECs are a market-based mechanism that represents a claim to the environmental benefits associated with renewable energy generation and consumption. One REC is created when a certain amount (e.g., one megawatt-hour, MWh) of green energy

\footnotetext{
${ }^{2}$ Margaret D. Fowler, Linking the Public Benefit to the Corporation: Blockchain as a Solution for Certification in an Age of “Do-Good” Business, VAND. J. ENT. \& TECH. L. 881, 885 (2018).

3 CT Corp, Staff, Benefit Corporations: FAQs, Wolters Kluwer (Jan. 7, 2016), https://ct.wolterskluwer.com/resources-center/article/benefit-corporations-faqs [https://perma.cc/39A5-245A].

${ }^{4}$ Ibid.

${ }^{5}$ Fowler, supra note 2 at 886.

6 National Renewable Energy Laboratory, Renewable Electricity: How Do You Know You Are Using It? (2017), 1, https://www.nrel.gov/docs/fyl5osti/64558.pdf.
} 
is generated and one REC is "spent” when a user applies this REC when consuming the same amount of power. All renewable energy tracking in the United States is based on RECs. ${ }^{7}$ Using RECs dovetails with general principles of economic efficiency by enabling parties that want (or have) to consume renewable energy to purchase it from other parties that have core strengths in generating renewable energy. ${ }^{8}$ RECs are an increasingly popular mechanism for corporations to meet their renewable energy targets, as evidenced by the increasing quantity of RECs created and transferred between entities over the last decade. ${ }^{9}$

The concept of REC is used most widely in the United States. The United States Department of Energy (DOE) recognizes that RECs "represent the technology and environment attributes of energy generated from renewable sources" and it affirms that they "can be sold separately from the mega-watt hour of generic electricity with which it is associated” (2008, p. 4). The United States Court of Appeals for the Second Circuit has also recognized that

...RECs are inventions of state property law whereby the renewable energy attributes are "unbundled" from the energy itself and sold separately. The credits can be purchased by companies and individuals to offset the use of energy generated from traditional fossil fuel resources or by government agencies to satisfy certain requirements that these agencies purchases purchase a certain percentage of their energy from renewable sources. ${ }^{10}$

According to the U.S. Environmental Protection Agency, "RECs were created to help convey the attributes of electricity generated from renewable resources to buyers...separated from the physical electricity, and as such, RECs are increasingly seen as the currency of renewable green power markets” (2008).

RECs, hence, are uniformly used as the primary means of tracking grid-connected renewable electricity generation, the ownership of, and rights to claim all of its associated attributes in the United States. ${ }^{11}$ RECs may be purchased directly from renewable energy project owners or through a third-party broker. They are typically verified so that the purchaser can claim sole ownership of the renewable power generated. Two types of RECs are available on the market: Bundled RECs constitute transactions where the underlying electricity and the green attributes of electricity are sold together. ${ }^{12}$ Unbundled RECs constitute transactions where the underlying electricity and the green attributes are sold separately. ${ }^{13}$

\section{Renewable Energy Certificates in the United States}

RECs were created in the mid-to-late 1990s to segregate renewable attributes from the generated electricity ${ }^{14}$ and because once electricity is "on the grid", it is impossible to determine its source. ${ }^{15}$ RECs solve

\footnotetext{
7 Renewable Choice Energy, The Value of Renewable Energy Credits 2 (Oct. 2015), http://www.renewablechoice.com/wpcontent/uploads/2015/10/Guide-To-RECs-White-Paper.pdf.

${ }^{8}$ Edward Holt, Jenny Sumner, and Lori Bird, The Role of Renewable Energy Certificates in Developing New Renewable Energy Projects 35 (June 2011), https://www.nrel.gov/docs/fyI losti/51904.pdf.

9 See Using Tracking Systems with the Implementation of Section 111(d) State Plans, Apx Research (Oct. 2014), https://www.eenews.net/assets/2015/06/08/document-cpp_05.pdf.

10 See Wheelabrator Lisbon, Inc. v. Dept. of Pub. Util. Control, 283 Conn. 672, 931 A. 2d 159 (2007).

11 Todd Jones, Robin Quarrier, and Maya Kelty, The Legal Basis for Renewable Energy Certificates (June 17, 2015), https://resource-solutions.org/wp-content/uploads/2015/07/The-Legal-Basis-for-RECs.pdf.

12 Matthew McDonnell, Kirsten Engel, and Ardeth Barnhart, Potential and Power of Renewable Energy Credits to Enhance Air Quality and Economic Development in Arizona, 43 ARIZ. ST. L. J. 809, 829 (2013).

${ }_{13}$ See Meredith Wingate and Ed Holt, Design Guide for Renewable Energy Certificate Tracking System, 4 (2004), https://www.nationalwind.org/wpcontent/uploads/assets/pastworkgroups/DesignGuideforREC_TrackingSystem_July_2004.pdf.

14 Ibid.

15 National Renewable Energy Laboratory, supra note 6.
} 
this problem by tracking the energy source through commercial transactions. ${ }^{16}$ REC buyers include both voluntary purchasers such as companies trying to achieve green energy targets and compulsory purchasers, such as utilities subject to RPSs. In the United States, many states have instituted RPSs requiring that a portion of electricity be generated from sustainable sources. ${ }^{17}$

RECs allow utilities and corporations to purchase renewable attributes from lower-cost providers, decreasing their aggregate renewable energy costs. RECs thus provide a primary mechanism for regulated utilities to meet required renewable energy portfolio standards mandated by states. ${ }^{18}$ However, it is important to note that not all states with RPSs allow RECs.

\section{REC Tracking System}

In the United States, RECs are tracked by 10 different registries created between 2002 and $2016 .{ }^{19}$ Some registries serve multiple states while others serve a single state. Each registry has its own operating instructions and acts as a voluntary association of participants financed either solely through user costs or through a mixture of state financing and user costs. ${ }^{20}$ Registries assign a unique identification number to each REC, or MWh generated, in a particular region so that a uniquely identified REC can only be in one tracking system account (e.g., owned by one account holder) at a time. ${ }^{21}$ By tracking unique RECs, state or provincial regulators can easily document renewable generation and sales and determine whether a power utility has met its renewable energy mandate. ${ }^{22}$ Tracking systems also ensure that: ${ }^{23}$ (1) RECs represent renewable generation; (2) Certificate ownership is transferred between account holders; (3) Certificates are retired when used to meet state or regional regulatory requirements; and (4) Certificates are not double-counted.

Currently, renewable energy generation is tracked using energy attribute certificates (EACs) and information sharing among market participants under a manual process: ${ }^{24}$ (1) When a renewable-power plant generates a unit of electricity, meters at solar and power plants record information onto a spreadsheet; (2) The spreadsheet is then sent to a registry provider, where the data gets entered into a new database; (3) Market intermediaries then connect buyers with sellers, vouching for the integrity of information on the certificate in exchange for a fee; and (4) Another party verifies the certificates after they are purchased and consumed. Not only is the current system time consuming, it also comes with high cost, potential for double counting, and accounting errors.

\footnotetext{
${ }^{16}$ Ad Hoc Working Group of Renewable Energy Res. Comm et al., Master Renewable Energy Certificate Purchase and Sale Agreement (V.1.0) (2007), http://resourcesolutions.org/images/events/rem/presentations/2008/ABA-EMAACORE\%20National\%20REC\%20AgreementJere my\%20Weinstein.pdf.

${ }_{17}$ Todd Jones, Two Markets, Overlapping Goals Exploring the Intersecting of RPS and Voluntary Markets for Renewable Energy in the U.S. 9-10, https://resource-solutions.org/wpcontent/uploads/2017/08/RPS-and-VoluntaryMarkets.pdf.

18 Galen Barbose, U.S. Renewables Portfolio Standards 2017 Annual Status Report 3, 28, \& 3 (July 2017), https://emp.lbl.gov/publications/us-renewables-portfolio-standards-0.

19 Center for Climate \& Energy Solutions, Renewable Energy Credit Tracking Systems, https://www.c2es.org/us-states-regions/policymaps/renewable-energy-credit-tracking.

20 Heeter, Renewable Energy Certificate (REC) Tracking Systems, Cost \& Verification Issues, 12-13 (Oct. 11, 2013), https://www.nrel.gov/docs/fyl4osti/60640.pdf.

21 Environmental Protection Agency, Renewable Tracking Systems, https://www.epa.gov/greenpower/renewable-energy-tracking-systems.

22 Meredith Wingate and Matthew Lehman, The Current Status of Renewable Energy Certificate Tracking Systems in North $\begin{array}{llll}\text { America } & 2 & \text { (Dec. }\end{array}$ http://www3.cec.org/islandora/en/item/2093-current-status-renewable-energy-certificate-tracking-systems-in-north-america-en.pdf.

${ }_{23}$ Environmental Protection Agency, supra note 22.

24 Dominic Barbato, Blockchain: Digitization of New Energy Opportunities for More Efficient Transactions, https://www.renewablechoice.com/blog-blockchain-new-energy-opportunities/.
} 


\section{Issues With Registry}

A registry performs a number of functions, such as giving RECs unique, identifying numbers: register and track REC transfers and retirements ${ }^{25}$; verify RPS compliance; support eco-labeling environmental disclosures; and substantiate green marketing claims ${ }^{26}$. However, registries do not act as an exchange. Registries also expressly denounce legal liability for title disputes between users in their Terms of Use and Operating Rules. This means that registries provide an information service, not brokerage, marketing, or legal service, creating numerous problems for the REC market. ${ }^{27}$

Possibility of double counting and fraud risk. The ten US registries act independently from one another so no registry can direct another registry's actions. This means developers and buyers must go through a costly, complicated, and opaque process that differs from market to market and rely on byzantine platforms to get the proof of green energy generation and purchases. Since registries do not communicate with one another unless an agreement exists between the registries and attestation provides the primary vehicle for authenticating RECs, the same REC could potentially be sold on two Registries. ${ }^{28}$ This situation, dubbed "double counting”, occurs when a REC generator offers the sale or use of the same certificate or attributes from one unit of renewable electricity to or by more than one person or entity. ${ }^{29}$ Moreover, the fragmented nature of current REC tracking systems in the United States seems inadequate because RECs are intangible, meaning that multiple ownership claims can arise and marketing abuses can occur. ${ }^{30}$ Although there is little evidence that double counting has occurred in the REC market, there is no reason to believe that it will not occur in the future, especially with the rapid growth of renewable energy both within and outside of the United States.

In a comparable market, egregious fraud occurred in the renewable identification numbers (RINs). RINs represent certificates issued by biodiesel suppliers that help regulated entities meet their EPA quotas for mandated use of biofuels. ${ }^{31}$ In United States $v$. Witmer, N.D. Ind., ${ }^{32}$ the co-owners of two biofuels processing plants in Waterloo, Indiana pleaded guilty to conspiracy, fraud, and false statements in connection with a scheme that generated more than $\$ 60$ million in fraudulent tax credits and renewable fuel credits. Frauds understandably threatened and harmed the credibility of the biodiesel industry. The experience in the RIN market indicates the propensity for fraud when dealing with paper certificate that are unbundled from a tangible good and RECs is susceptible to the same type of fraud that occurred in RIN market. ${ }^{33}$

Regulatory challenges. As no federal registry for RECs currently exist, multiple REC tracking systems exist in the United States with different data being tracked by divergent processes. ${ }^{34}$ The Federal Trade Commission (FTC)'s 2013 binding rule provides authoritative guidance related to environmental marketing

\footnotetext{
25 Renewable Choice Energy, The Value of Renewable Energy Credits 3 (Oct. 2015), http://www.renewablechoice.com/wpcontent/uploads/2015/10/Guide-To-RECs-White-Paper.pdf.

${ }_{26}$ Edward A. Holt, \& Ryan H. The Treatment of Renewable Energy Certificates, Emission Allowances and Green Power Programs in Stare Renewables Portfolio Standards, 4 (Apr. 2007), https://emp.lbl.gov/sites/default/files/report-lbnl-62574.pdf.

${ }^{27}$ Lisa Koperski, Why the Renewable Energy Credit Market Needs Standardization, 13 Wash. J. L. Tech. \& Arts 69, 92 (2017).

${ }^{28}$ Ibid.

29 North America Association of Issuing Bodies Working Group, Double Counting Best Practices 1 (May 5, 2006), https://resourcesolutions.org/wpcontent/uploads/2017/06/FinalWGDecisionDraftNAAIBDoubleCountingbestpractices9.pdf.

30 Edward Holt \& Kevin Porter, Powering the Plains, Midwest Renewable Energy Tracking System Concept Paper 8 (Sept. 1, 2004), http://www.mrets.org/wp-content/uploads/2014/03/Credit-Tracking-Concept-Paper-9-22-04.pdf.

31 Beeta Lashkari, Comparing Verification of Renewable Fuel and Carbon Credits, 3 Renewable Energy L. \& Pol’y Rev. 229 (2013).

32 No. 1:16 CR 64 (N.D. Ind. Mar. 1, 2017).

33 Koperski, supra note 27 at 96.

${ }^{34}$ Ibid., at 101.
} 
claims. ${ }^{35}$ The guidance specifies that renewable energy claims need to have substantiation for all their express and reasonably implied claims and be "clearly and prominently" qualified, as necessary. ${ }^{36}$ This rule states that products should not be advertised in an unqualified manner as "made with renewable energy" unless "virtually all[,] of the significant manufacturing processes involved in making the product or package are powered with renewable energy or non-renewable energy matched by renewable energy certificates”. ${ }^{37}$ In light of this and other regulations, PBCs should focus more than sourcing their renewable energy at competitive price, but also make verifiable claims about purchases in order to ensure that no other entity is making the same claim from the same source.

\section{Recommendations for Corporate Renewable Energy Procurement}

The issue for REC procurement in the United States is straightforward; the regional registry structure lacks standardization because each registry has different policies for tracking RECs. So, while regional registries effectively act as clearinghouses to create, verify, track, and retire RECs, they impede the free-flow of supply and demand for RECs on a national basis and may artificially inflate REC costs in certain markets. ${ }^{38}$

\section{Enter the Blockchain}

Standardization of REC verification is a long-term goal. In order to address the fragmented REC market, it might be wise to look into technology and how it could help to resolve the issue. One such potential tool is blockchain. Blockchain offers an alternative method for combatting double counting and fraud, delivering transparency and trust to the marketplace. Because even though each REC has its own serial number, it can be difficult for a customer and the public to independently audit the use of RECs or otherwise determine that a specific REC has not been placed on another registry, has not been retired, and actually exists. ${ }^{39}$

Blockchain is an electronic ledger of digital records, events, or transactions that are cryptographically hashed, authenticated, and maintained through a "distributed" or "shared" network of participants using a group consensus protocol. This technology creates a system based on cryptographic proof instead of trust, allowing any two willing parties to transact directly with each other without the need for a trusted third party. To do so, each party to the transaction has two keys: a public key which is known to the world and a private key which is kept secret. Similar to existing digital signature technologies, a sender generates a digital signature from her private key which can be verified by anyone using their public key. ${ }^{40}$ A blockchain user or group of users will cryptographically hash the record of any transaction; this hash will be broadcast to the network that a particular transaction has occurred. ${ }^{41}$ Once the information is on the block, any change requires practically the entire network to agree on the change, ${ }^{42}$ making it almost impossible to alter or remove the records.

Using blockchain, distributed ledgers have the potential to eliminate auditing, lower transaction, and certification costs, and avoid non-market price controls. This makes renewable-energy investment attractive

\footnotetext{
35 Guides for the Use of Environmental Marketing Claims, 16 C.F.R. §260.15 (2012).

36 16 C.F.R. § 260.15 (b) \& (c).

37 16 C.F.R. § 260.15 (c).

38 Holt, supra note 30.

${ }^{39}$ Koperski supra note 27 at 101.

40 James Condos, William Sorrell, and Susan Donegan, Blockchain Technology: Opportunities and Risks (January 15, 2016), https://legislature.vermont.gov/assets/Legislative-Reports/blockchain-technology-report-final.pdf.

41 Ibid., 8.

42 Katherine Heines, The Risks and Rewards of Blockchain Technology, 63 Risk Management 4, 6-7 (2016).
} 
even for small players. ${ }^{43}$ Blockchain also makes market intermediaries redundant as accreditation and validation functions are now integrated into transaction protocols. One major advantage of blockchain is the immediate creation of RECs. RECs can be created instantaneously as renewable energy is put onto the grid, no matter the size or physical location of the producer. ${ }^{44}$ This immediate production creates a verifiable chain of custody for renewable energy attributes and helps ensure clean energy producers to receive credit for the energy they generate while prohibiting the double-counting of energy attributes, among other functions.

Reliability and accuracy issues with blockchain. With its promises, a report by the State Government of Vermont found several issues with the use of blockchain, such as cost and environmental impact. Most importantly, the downside of blockchain is that although it can guarantee the record's authenticity by confirming the party submitting a record, the time and date of the submission, and the contents of the record at the time of submission, blockchain does not address reliability and accuracy of the content. ${ }^{45}$ The information will only be as good as the entity (human or machine) entering the information. ${ }^{46}$ If bad data is used as an input, as long as the correct protocols are utilized, it will be accepted by the network and added on to the blockchain. ${ }^{47}$ Furthermore, blockchain makes correcting mistakes difficult because transactions are not reversible, meaning that high accuracy at the onset is critical. ${ }^{48}$

Solving reliability and accuracy issues via smart contract. Blockchain is considered as a disruptive technology by many and as a relatively new form of technology, many of the issues can be expected to be addressed over time. The issues raised by the State of Vermont are typical for "Blockchain 1.0". This stage of blockchain is best known to the public through Bitcoin, the virtual currency that can be used as an alternative to fiat currency in some jurisdictions. In order to overcome the issues raised by the State of Vermont, one should progress to "Blockchain 2.0", a stage which smart contracts are utilized. A smart contract represents a digital protocol that automatically executes predefined processes of a transaction without requiring the involvement of a third party. According to Nick Szabo, smart contracts are,

a set of promises, including protocols within which the parties perform other promises. The protocols are usually implemented with programs on computer network, or in other forms of digital electronics, thus these contracts are "smarter" than the paper-based ancestors. No use of artificial intelligence is implied. (1996)

Smart contracts can be embedded with advanced control criteria that allow only authorized users to create transactions. Relevant criteria could be encoded in smart contracts to ensure all conditions have been met before the conclusion of a contract. Hence, it would be possible to create a fully automated smart contract between a different parties selling, buying and verifying REC. Ultimately, the establishment of decentralized autonomous organization (DAO) is to manage and use smart contracts to transcribe governance into a blockchain. In short, the appeal of smart contract lies in (1) the digitization of trust through certainty of execution, and (2) the creation of efficiency through removal of intermediaries and the costs they bring to the

\footnotetext{
${ }^{43}$ Kimberly Henderson, Emily Knoll, and Matt Rogers, What Every Utility CEO Should Know About Blockchain (Mar. 2018), https://www.mckinsey.com/industries/electric-power-and-natural-gas/our-insights/what-every-utility-ceo-should-know-about-bloc kchain.

${ }^{44}$ Barbato, supra note 24.

45 Condos, supra note 40 at 10.

${ }^{46}$ Garry Gibson, Policy Consideration for the Blockchain Technology Public and Private Applications, SMU SCI. and Tech. L. Rev. 327, 343 (2016).

47 Condos, supra note 40 at 10.

${ }^{48}$ Gibson, supra note 46 at 343.
} 
transactions. $^{49}$

Currently, the most advanced smart contract enabled blockchain is called Ethereum. The blockchain is characterized as being "Turing complete", which means that they are fully functional and can perform any computation that you can do in any other programming language. This provides a solid rationale for using blockchain in the REC market because while proponents of the current system might say that attestation alone is enough since independent parties can validate and certify renewable energy to a REC purchaser, the fact remains that the landscape is complicated by the multitude of certification schemes. ${ }^{50}$ It remains unclear however, if REC users, registries, and administrators would embrace blockchain to solve these real, but unquantified risks. But some real world applications have begun to take shape, with major companies such as IBM, Kroger, and Walmart recently announcing plans to utilize blockchain for activities like food safety and streamlining payment processing. They may provide test cases for using blockchain in the REC market. ${ }^{51}$

\section{Conclusion}

Combating climate change and finance green projects through the purchase of RECs enables a win-win situation for both the energy supplier and the credit buyer. But issues remain to be addressed. This paper has identified the issue of fragmentation in the REC market in the United States which might lead to the potential danger of double counting and fraud. Although a national wide registry for REC verification is lacking, companies could embrace new technologies such as blockchain to ameliorate these concerns. Some large corporations have started pilot projects to test the feasibility of using blockchain but the mechanism on how blockchain can help verify REC remain a topic for future studies.

\section{References}

U.S. Department of Energy Office of Energy Efficiency and Renewable Energy, Federal Energy Management Program (FEMP). $\begin{array}{lllllll}\text { (January 28, 2008). } & \text { Exec. } & \text { Order } & \text { No. } & 13, & 423 . & \text { Section }\end{array}$ 2.2.12. http://www1.eere.energy.gov/femp/pdfs/epact05_fedrenewenergyguid.pdf

$\begin{array}{lllll}\text { Environmental } & \text { Protection } & \text { Agency. } & \text { (2008). } & \text { Renewable }\end{array}$ http://www.epa.gov/greenpower/documents/gpp_basics-recs.pdf

\footnotetext{
${ }^{49}$ Cheng Lim and T. J. Shaw, "Smart Contracts: Bridging the Gap Between Expectation and Reality”, Oxford Law Faculty Business Law Blog, https://www.law.ox.ac.uk/business-lawblog/blog/2016/07/smart-contracts-bridging-gap-between-expectation-and-reality.

${ }^{50}$ Koperski, supra note 27 at 101.

51 Frederic Lardinois, IBM, Kroger, Walmart and Others Team Up to Improve Food Safety With Blockchains, Techcrunch (Aug. 22, 2017), https://techcrunch.com/2017/08/22/ibm-costco-walmart-and-others-team-up-toimprove-food-safety-with-blockchains/.
} 